\title{
La supuesta invasión del siglo III d.C. en territorio de vascones
}

\author{
Raquel lópez Melero*
}

Durante el siglo III d.C. el Imperio Romano se vio perturbado, tanto en Oriente como en Occidente, por reiteradas invasiones de bárbaros; y la Peninsula Ibérica, aunque ocupaba una posición periférica respecto de los centros de poder, no dejó de sufrir las consecuencias de alguna de esas invasiones. Diversas fuentes de información documentan la entrada en Hispania de francos y germanos en torno al 260 d.C., dentro de un amplio panorama de invasiones y usurpaciones '.

Aurelio Víctor, primer autor que alude a esa invasión, y de quien dependen las otras referencias total o parcialmente, identifica como francos a los invasores, y lo mismo hace Nazario; los demás autores, en cambio - Eutropio, Orosio, Jerónimo y Próspero de Tiro-, utilizan para ellos el término "Germani». De ahí que la historiografía moderna haya dado en emplear la mención doble de francos y alamanes, que no se refiere a dos invasiones diferenciadas en el tiempo.

* U.N.E.D.

' Aurelio Victor. Lib. de Caes. 33, 3: (Gallienus) rem Romanam quasi naufragio ... dedit ... adeo uti... Francorum gentis direpta Gallia Hispaniam possiderent vastato ac paene direpto Tarraconensium oppido, naetisque in tempore navigiis pars in usque Africam permearet...; Eutropio, 8, 8, 2: Germani usque ad Hispanias penetraverunt et civitatem nobilem Tarraconem expugnaverunt...; Orosıo, 7, 22, 7: ... Germani ulteriores abrassa potiuntur Hispania ... exstant adhuc pers signa miseriarum et nominum iudicia servantes, ex quibus nos quoque in Hispania Tarraconem nostram ad consolationem miseriae recentis ostendimus; Nazario, Paneg. Constant. August. 17, 1: Franci ipsi praeter ceteros truces quorum vis cum ad bellum affervesceret uitra ipsum occeanum aestu furoris evecta. Hispaniarum etiam oras armis infestes habebant; JERONImo. Chron., p. 1830 (ed. Schoene): Germanis Hispanias obtinentibus Tarraco expugnata est: DE TIRO, Próspero, Epit. Chron., págs. 441, 879: Germanis Hispanias optinentibus Tarracona expugnata est. 
Las referencias literarias a tal invasion son de un tono muy general y demasiado parcas en contenido, viniendo a coincidir mayoritariamente en dos aspectos: la constatación de que hubo invasión y el hecho de que afectó a la ciudad de "Tarraco". Y el caso es que una información tan exigua no permite suponer, ni aun sospechar, que lo sufrido por "Tarraco" sea generalizable a otras muchas ciudades. Como tampoco hay, de hecho, base para pensar que en esa Historia Abreviada de Aurelio Victor se esté mencionando a "Tarraco", en su calidad de ciudad muy importante, a modo de paradigma ilustrativo de lo que aconteciera a otras ciudades silenciadas por las fuentes.

Aurelio Victor y Orosio aportan sendas indicaciones adicionales significativas. Dice el primero que un grupo de esos invasores (pars), apoderándose de naves -en una cuantia que no se especifica- (nactisque in tempore navigiis), se embarcaron por África. $Y$ Orosio, refiriéndose con gran probabilidad a esa invasión, testimonia con la frase "y lo sufrieron incluso durante casi doce años en una invasión de germanos, en la época del emperador Galieno" ${ }^{2}$ la permanencia de dichos bárbaros en Hispania durante casi doce años. Desconocemos en verdad la fuente de la que tomo Orosio el dato en cuestión, que los demás autores parecen ignorar, pero, en cualquier caso, el caracter incidental que tiene su mención en el texto no inclina precisamente a pensar que sea una invención del autor. Por desgracia, la indicación de esa permanencia tan prolongada de los invasores en nuestro suelo es de tipo general, sin precisión alguna de lugares o territorios.

Asi, pues, la documentación literaria en nuestro haber con respecto a la llamada invasión de francos y alamanes es tan limitada en todos los sentidos que no permite valorar el volumen de las destrucciones llevadas a cabo ni las repercusiones producidas en la vida económica; para ello hay que recurrir a la constatación arqueológica de destrucciones datables en el siglo III d.C., o bien a indicios indirectos, tales como la distribución de los tesorillos monetales, supuestamente ocultados para hurtarlos al invasor, o el amurallamiento de ciertas ciudades, atribuible a una situación de peligro inminente. Tomando como base esa evidencia exclusivamente arqueológica, algunos investigadores modernos han venido a presentar un amplio panorama geográfico de la incidencia de la invasión,

${ }^{2}$ Orosio. 7. 41. 2: Inruptae sunt Hispaniae. caedes vastationesque passae sunt: nihil quidem novum, hoc enim nunc per bienum illud. quo hostilis gladius saeviitt, sustinuere a barbaris, quod per ducentos quodam annos propemodum duodecim Germanis evertentibus exceperunt. 
con identificación de los lugares que habrían sufrido la acción directa de los bárbaros, o la amenaza, en su caso ${ }^{3}$. El problema es que muchos de los yacimientos excavados no cuentan con una valoración lo suficientemente precisa como para que se puedan establecer puntualizaciones cronológicas ciertas, de suerte que la atribución de las destrucciones y los incendios constatados a los invasores de referencia es en gran medida intuitiva; quizá en muchos casos no era posible hacer una valoración rigurosa de los datos arqueológicos, y eso ha propiciado el dictamen apriorístico ${ }^{4}$.

Con respecto al amurallamiento de las ciudades, hay que decir que los trabajos de fortificación no siempre persiguen fines exclusivamente defensivos, ya que también entran en juego en la construcción o reconstrucción de la murallas motivos de prestigio, exponentes por cierto de

${ }^{3}$ Ver al respecto SÁNCHEZ ReAL, J., "La invasión germánica del 259 en Tarragona", Bol. Arqueol. Tarrac., 51, 1951 , págs. 129 ss.; İdem, "Las invasiones germánicas", Instituto de Estudios Tarraconenses. Sección de Arqueologia e Historia, publicación núm. 16, 1957, págs. 5-11; TARRADELL, M., "Sobre las invasiones germánicas del siglo II d.C. en la Península Ibérica", Estudios Clásicos, 3, 1955, págs. 95-110; Ídem, “Problemas cronológicos de las invasiones germánicas del siglo III d.C.", IV CAN, Zaragoza, 1957, págs. 231-239; Ídem, "La crisis del siglo III d.C. en Hispania: algunos aspectos fundamentales", I Congreso Español de Estudios Clásicos, Madrid, 1958, págs. 263-275; BALL, A., «Las invasiones germánicas en Hispania durante la segunda mitad del siglo il d.C.", Cuadernos de Trabaj. de la Escuel. Españ. de Hist. y Arqueol. en Roma, 9, 1957, págs. 97-145, y en Anales de Historia Antigua y Medieval, 1957-1958, págs. 49-91; Ídem, "Hispania en los años 260 a 300 d.C.", Emerita, 27, 1959, págs. 269-295; Ídem, "De Marco Aurelio a Constantino", Hispania, 27, 1967, págs. 245-341; RAMOS Foloues A. "Las invasiones germánicas en La Alcudia (Elche)", I Congreso Español de Estudios Clásicos, Madrid, 1958, págs. 275-279; Ídem, "Las invasiones germánicas en la provincia de Alicante", Instit. de Est. Alicantinos, Alicante, 1960, págs. 9-53; İdem, "Las invasiones de francos en Hispania", Anales de la Universidad de Murcia, 23, 1964-1965; Blazouez, J. M.a "La crisis del siglo III en Hispania y Mauritania Tingitana", Hispania, 108, 1968, págs. 5-37, y "La crisis del siglo II en Hispania y Mauritania Tingitana", en Economia de la Hispania Romana, Bilbao, 1978, páginas $461-483$.

${ }^{4}$ Ya A. Balil en sus distintos trabajos referentes a este tema se mostraba muy cauteloso, aunque admitía la invasión y los efectos derivados de la misma, a la hora de aplicar mecánicamente el criterio de destrucción-invasión, advirtiendo que en modo alguno respondía a una ecuación ineludible. $Y$, en efecto, de nuevas excavaciones y valoraciones de lugares que anteriormente se suponia habian sido destruidos, resulta que no lo fueron, $o$ que su destrucción fue somera, parcial y limitada, quedando, además, en entredicho su atribución a los invasores. Asi, frente a lo que anteriormente se suponia, la ciudad de "Baetulo" no presenta huellas evidentes del paso de esos invasores. Ver al respecto GuItART DURÁn, J., Baetulo. Topografía arqueológica, Urbanismo e Historia, Badalona, 1976, pág. 245. Tampoco la villa del Pla de l'Horta presenta huellas de haber sido destruida o sensiblemente afectada en esta época; ver Nolla Bufrau, J. M., "Algunes notes entron de la villa del Pla de l'Horte a Sarriá de Dalt (Girona)", Annals, 1984, págs. 122-123. Tampoco parece decaer la actividad económica en algunas tierras de Valencia; ver FERNANDEZ IZ. oulerdo, A., Las ánforas romanas de Valencia y de su entorno marítimo, Valencia, 1984. págs. 101 y 103. 
una situación económica relativamente boyante. Habria que establecer, pues, cuáles son las ciudades hispanas que se fortifican por causa de los invasores, y eso no es nada fácil. Por otro lado, resulta altamente problemática la sincronización, a base de criterios arqueológicos, de ciertas fortificaciones de ciudades con un momento subsiguiente a la invasión. De hecho, se han apreciado indicios, aunque no decisivos, de carácter general que inducen a situar las reconstrucciones de murallas en época muy posterior a las invasiones francas ${ }^{5}$.

También las ocultaciones monetales pueden responder a causas diversas, intimamente asociadas, eso sí, por lo general, a factores de intranquilidad o de violencia. El caso de las Galias ${ }^{6}$ ha movido a algunos investigadores a relacionar tales factores en determinadas ocultaciones monetales peninsulares con los invasores franco-alamanes, hasta el punto de suponer que su distribución geográfica marcaba el camino seguido por éstos a lo ancho y a lo largo del territorio hispano.

Pero esa argumentación suscita ciertas reservas. Por una parte, hay que tener presente que la pieza más reciente de un tesorillo sólo proporciona un terminus post quem para la ocultación del mismo, no una data precisa, de modo que los sincronismos establecidos con las invasiones no pasan de ser hipotéticos. Por otra parte, ocurre a veces que la moneda más reciente de un tesorillo se atribuye, sin más precisiones cronológicas, a un emperador de largo mandato; en los casos, sobre todo, en que no se dispone de un estudio pormenorizado de las series en cuestión, la propia moneda comporta unos márgenes importantes de incertidumbre en lo tocante a la datación, que dificultan todavia más cualquier sincronismo. $Y$, en fin, en cualquier caso, los tesorillos que se

${ }^{5}$ Para las ciudades que se supone que se fortificaron como consecuencia de la invasión franca, ver BLAZQUEZ, J. M. ${ }^{a}$, "La crisis del siglo II", obra citada, págs. 24-25; Idem, Historia Económica de la Hispania Romana. Madrid, 1978. pags. 237-238. Sobre las fortificaciones ver RICHMOND, 1., "Five Town-Walls in Hispania Citerior", J.R.S. 21, 1931, págs. 86 ss.; BaLIL, A., "Sobre las fortificaciones del Bajo Imperio en Hispania. Las puertas de la muralla de Barcino", I Congreso Español de Estudios Clásicos. Madrid, 1958, págs. 279 ss.; Idem, "La defensa de Hispania en el Bajo Imperio. Amenaza exterior e inquietud interna", Legio VII Gemina, Leon, 1970, págs. 601 ss.

${ }^{6}$ Para la distribución de estos tesorillos en las Galias ver BLANCHET, A.. Les Tresors de monnaies romaines et les invasions germaniques en Gaule. Paris, 1900. Para el estudio y distribución de los tesorillos en las Galias ver KOETHE, H., "Zur Geschichte Galliens im dritten Viertel des 3. Jahrhunderts", Ber. Röm. Germ. Komm., 32, 1950, págs. 199-224; LAFauRie, J., "L'Empire Gaulois. Apport de la Numismatique", A.N.R.W., II, 2, 1975, págs. 853-1012. 
suelen relacionar con las invasiones ${ }^{7}$ siempre quedan pendientes de la cuestión de si fueron realmente ocultados por causa de las mismas. Las dataciones -que a veces por falta de datos abarcan varios años del reinado de un emperador - atribuidas, por la moneda más reciente, a los tesorillos de Valverde del Camino (Jaén), de Jimena de la Frontera (Castellón de la Plana), de los dos de Tarragona, de Altafullá y de Rosas ${ }^{8}$ no sólo indican que algunos de esos tesorillos son posteriores a la invasión, sino que no proporcionan una secuencia cronológica norte-sur, como cabría esperar en razón de la presumible trayectoria de los invasores en su camino de progresión. Por supuesto que ello no excluye la posibilidad de que tales ocultaciones monetales sean debidas a la invasion, porque, si en verdad permanecieron los inmigrantes doce años en nuestro suelo, como parece constatar Orosio, pudieron llevar a cabo movimientos alternativos de avance y retroceso, pero el caso es que la interrelación de esas dataciones no ayuda a establecer la conexión entre tesorillos e invasiones, que es de la mayor importancia.

Así, recientemente algunos investigadores, ante la dificultad de datar de un modo preciso la fortificación o la reconstrucción de las murallas de algunas ciudades hispanas - que, como deciamos, podrian tener motivaciones no sólo defensivas-, ante el estudio más sustancioso de algunos de los tesorillos ocultados y ante nuevas consideraciones arqueológicas, que minimizan, o simplemente no perciben los efectos de

BALIL, A., "Las invasiones germánicas...", obra citada, págs. 125-131; Idem, en Anales de Hist. Antig. y Medieval, obra citada, págs. 72-81; BLAzouez, J. M. ${ }^{2}$ " "La crisis del siglo III en Hispania, obra citada. págs. 19-24: Idem. Historia Economica de la Hispania Romana, obra citada, págs. 232-236.

${ }^{8}$ El tesorillo del Valverde del Camino (ver BALIL. A., "Las invasiones germanicas...". obra citada, pág. 142) ofrece como moneda más reciente la de Galieno. lo que nos situaria en un espectro cronológico entre el 253 y el 268. En el tesorillo de Jaén (ver Mateu r LLOPIS, F., "Hallazgos monetarios XV", Num. Hisp., VII, 1958, pág. 73) las monedas más recientes parecen corresponder al período 261-268. Las últimas del sustacioso tesorillo de Jimena de la Frontera (ver Christol, M., Y NonY, D., "Trésor de Jimena de la Frontera (Cádiz): antoniniani du III siècle", B.S.F.N., 5, 1970, págs. 526-528) corresponderia al 267-268. Las últimas monedas del pequeño tesorillo de Castellón de la Plana (ver MATEU y LLOPIS, F.. "Hallazgos monetarios. VII". Num. Hisp., I, 1952, págs. 244-245) serían del 261. En uno de los tesorillos de Tarragona (ver BALIL. A. "Las invasiones...", obra citada, pág. 141) las últimas monedas corresponderian al gobierno de Galieno; en el otro (ver HIERNARO, J., "Recherches numimastiques sur au \|\|$^{\text {eme }}$ siècle aprés J.C.". Numisma. 150-155, 1978. págs. 315-316) las más recientes corresponderian al año 266; este seria el año de la moneda más reciente del tesorillo de Altafullá (ver MATEU Y LLOPIS, F., "El hallazgo de denarios romanos de Altafullá", B.A.L., 30, 1950, pág. 53-58). La más reciente del tesorillo de Rosas (ver Gurt, M ${ }^{a}$. "Comentario sobre un lote de monedas de Póstumo", Gazeta Numism., 45, 1977, págs. 10-13), correspondiente a este emperador, se situaria en el año 267. 
una invasión en determinados lugares considerados antaño como exponentes de tal hecho, niegan o reducen mucho las consecuencias de la invasión franco-alamana ${ }^{9}$.

$Y$ es que, ciertamente, cuando la información literaria es tan escasa e inconcreta - sólo se constata de hecho la parcial destrucción de "Tarraco»- y cuando la evidencia numismática y arqueológica es imprecisa y problemática, resultará siempre difícil establecer una relación de causa a efecto entre la invasión y una ocultación monetal o una destrucción determinadas. Semejante conexión será siempre una hipótesis abierta; más verosímil, en principio, en la zona catalana y el norte del Levante, bastante menos en otras áreas peninsulares.

Hace ya bastantes años $B$. Taracena ${ }^{10}$ publicó un trabajo especifico sobre las invasiones franco-alamanas. Tomando como base las destrucciones apreciadas, entre otros puntos, en la villa de Liédena y en la ciudad de Clunia, y en razón también de los tesorillos procedentes de esos lugares, conjeturó una segunda invasión germánica de nuestro territorio, aunque era consciente de que no existia información literaria de la misma con respecto al suelo hispano. Fundamentaba su hipótesis indirectamente en la importante invasión de las Galias de 275 d.C., que obligara a M. Aurelius Probus a emplearse a fondo contra los longiones, cuyo jefe fue capturado; contra los francos, que fueron derrotados, y contra los germanos, que fueron incorporados al ejército romano, al mismo tiempo que quedaban reforzadas las defensas del Rin. Las inscripciones honorificas conmemoran estos triunfos otorgando a Probo el título de "Germanicus" (I.L.S. 597), y los rótulos monetales (RIC 5.2.40), lo mismo que determinada documentación literaria (Zós. 1.67-68), recuerdan su "victoria germánica».

Está claro que la invasión de las Galias revistió tintes serios y alarmantes, por lo que no resulta extraño, en principio, que, aunque no lo reflejasen las fuentes literarias, algún grupo de esos bárbaros hubiera

9 Ya BALIL, A., en diversos trabajos se mostró bastante restrictivo respecto a los efectos de esta invasión y al área geográfica que pudieron alcanzar. ARCE, J., "La crisis del siglo III d.C. en Hispania y las invasiones bárbaras", H. A., VIII, 1978, págs. 5-37, lleva la crítica a muchos de los datos utilizados - fortificaciones, excavaciones, tesorillos- como puntos de apoyo para suponer la presencia de esos invasores en algunos lugares del suelo hispano. Es SAGRedo, L., "Las invasiones del siglo III d.C. en Hispania a la luz de los tesorillos monetales", H. A., XI-XII, 1981-1985, págs. 89-104, el que de forma más pormenorizada desde el punto de vista numismático analiza las invasiones para negar que guarden relación con los tesorillos.

${ }_{10}$ Ver TaRacena, B., "Las invasiones germánicas en España durante la segunda mitad del siglo III, I Congreso Internacional de Pirenaistas. Zaragoza, 1950. págs. 5-13. 
llegado a infiltrarse por los Pirineos occidentales. El caso es que la propuesta de Taracena tuvo un eco muy favorable, y algunos investigadores pusieron en relación con esa supuesta invasión determinados incendios detectados en «villae» y ciudades del Valle del Ebro y de la Meseta, asi como el receso económico que se intuye en algunas de ellas, en razón de la escasez de datos que las iluminan en ese período ${ }^{11}$, aunque otros investigadores se muestran mucho más restrictivos ${ }^{12}$.

Así, pues, la invasión, o invasiones, de la Peninsula ha funcionado como un socorrido término de referencia a la hora de interpretar determinados datos arqueológicos fechables en el siglo III d.C., que, en teoria, podrían corresponder igualmente a incendios fortuitos o a revueltas locales por ejemplo. No hay que olvidar en todo caso que la invasión de la que se tiene noticia penetró por los Pirineos orientales y, que sepamos, sólo destruyó parcialmente la ciudad de "Tarraco"; como no hay que olvidar tampoco que las huellas de destrucción de otras ciudades, atribuidas a las invasiones, no son claras. Por otra parte, el hecho de que una "pars" de los invasores se embarcara en dirección a África sugiere

$"$ TARRADELl. M.. con las cautelas que le merece una propuesta elaborada a partir de datos arqueológicos no muy claros y definitivos, acepta con prudencia la posición mantenida por B. Taracena. Ver al respecto TARRADELL, M., "Sobre las invasiones germánicas del siglo III d.C. en la Península Ibérica", Estudios Clasicos...", obra citada, passim: "Problemas cronológicos de las invasiones germánicas del siglo II d.C.", IV CAN.., obra citada, passim; "La crisis del siglo III d.C. en Hispania: algunos aspectos fundamentales". I Congreso Español de Estudios Clásicos..., obra citada, passim. La destrucciones que TARRACENA, B., constató en la villa de Liédena y el tesorillo monetal encontrado en la misma le inclinaron a suponer que era consecuencia de una segunda invasión bárbara, siendo seguido en ello en trabajos recientes. Ver al respecto Blazouez, J. M. " "La crisis del siglo III en Hispania y Mauritania Tingitana", Hispania, 108, 1968, pág. 11; Ídem, Economia de la Hispania romana, Bibao, 1978, pág. 465; Idem, Historia economica de la Hispania romana, Madrid. 1979, pág. 229. También Revilla, P.; De Palol, A., y Cuadros, A., Excavaciones arqueológicas en la villa romana del "Cercado de San Isidro". Parcela "Villa Possidica". Dueñas (Palencia), Madrid, 1962, pág. 9, consideran que de algunas de estas destrucciones pudieron ser quizá causantes los invasores franco-alamanes. Recientemente. PEREX. M. ${ }^{a}$ J., Los Vascones, Pamplona, 1986, pág. 171, y BlAzouez, J. M." ("Arte y Sociedad de los mosaicos romanos de Navarra". Primer Congreso General de Historia de Navarra. Anejo 7 de Prin. cipe de Viana. Comunicaciones, Pamplona, 1987, pág. 316).

12 Con sólidas razones parte de la historiografia actual tiende. grosso modo, a restringir a la zona catalana y norte de Levante. y dentro de ellas a lugares concretos — «Tarraco» el área de destrucciones atribuibles a la invasión franco-alamana del 260 mencionada por las fuentes literarias. De manera semejante se supone que fueron muy pocos los tesorillos, entre ellos el de Altafullá (Tarragona) y Castellón, que se ocultarían como consecuencia del temor ante la inminente presencia de esos invasores. Ver ARCE. J., "La crisis del siglo II" d.C. en Hispania y las invasiones bárbaras". H.A., 8, 1978, págs. 257-269; Sagredo, L., "Las invasiones del siglo II d.C. en Hispania a la luz de los tesorillos monetales", $H$. $A$., $11-12,1981-1985$, págs. 89-104. 
que no tenian demasiado abierta la vía de expansión por la Península, al tiempo que indica que se vieron mermados en sus efectivos $y$, consecuentemente, en su capacidad de destruir, sobre todo ciudades; porque, si bien es probable que por entonces muchas de ellas estuvieran sin amurallar y resultaran vulnerables, también cabe suponer que utilizaran para su defensa todos los efectivos humanos disponibles que la legislación municipal permitía movilizar, al margen de la acción de las tropas. Por último, señalar una vez más que desconocemos por completo el área de dispersión de los invasores en su acción destructora; es verdad que si permanecieron en Hispania doce años, como dice Orosio, pudieron hacer mucho daño, pero también parece extraño que no haya constancia en esa noticia de intervención alguna por parte del ejército acantonado en la provincia Tarraconense, o de alguna de sus unidades, para la persecución y represión de los intrusos, que habria tenido que producirse si en verdad estaban ejerciendo una acción devastadora.

Como ya se ha dicho, la incidencia en las ciudades de la primera y de la supuesta segunda invasión se rastrea tomando como indicios positivos la ocultación de tesorillos, el amurallamiento y los incendios o destrucciones efectiva o potencialmente sincronizables con la entrada de los bárbaros. Al margen de los problemas que plantea cada uno de esos marcos de evidencia en particular, su aplicación como criterios comporta una limitación importante con respecto al territorio de los vascones. Muchas ciudades vasconas, como Aracilus, Bitouris, Cournonion, Mouscaria - Nemantourista, al estar sin identificar son meros nombres en las fuentes literarias y epigráficas ${ }^{13}$. Otras, como Alauona, laca, llumberri, Iturissa, Oeasso, Segia, Tarraga, Graccuris, Cascantum o Andelos ${ }^{14}$, con

13 Para estas cuestiones ver SAyAs ABEngochea. J. J., «El poblamiento romano en el área de los vascones". Veleia, I, 1984, págs. 300 ss. Los habitantes de la ciudad de los "Aracellitani" (Plinio, N. H., III, 3, 24, It. Ant. 455, 3) pueden estar relacionados con el movimiento bagaudico (SAYAS ABEnGOCHEA, J. J., "Consideraciones historicas sobre Vasconia en epoca bajoimperial», en La Formación de Alava. 650 Aniversario del Pacto de Arriaga, Vitoria, 1984, pág. 189-236; Idem, "Los Vascones y la Bagaudia", en Asimilación y resistencia a la romanización del Norte de Hispania. Vitoria, 1985, págs. 189-236. Bitouris (sin identificar y sólo aludida por Ptolomeo, II 6, 67), Cournonion (Ptolomeo, Il, 6. 67. La inscripción CIL. XIII, 621 se refiere a un miembro de esta comunidad), Ergaouia (Ptolomeo, II, 6, 67), Mouscaria (Ptolomeo, II, 6, 67), Nemantourista (Ptolomeo, II, 6, 67).

${ }^{14}$ «Alauona» se identifica con Alagon (Zaragoza). No se han realizado excavaciones en el Alagón actual. Lostal, J., Arqueologia de Aragón romano, Zaragoza, 1980, pags. 105119. Las referencias literarias y numismáticas de momentos anteriores hacen pensar que era una ciudad de relativa importancia que comenzó a declinar en beneficio de "Caesaraugusta". "laca" (Jaca, Huesca). No conocemos gran cosa de esta ciudad para esos momentos. CeAN BERmudez, A. (Sumario de las Antigüedades romanas que haya en España. Madrid, 1823, pág. 149) habla de restos de murallas que los considera como probablemente romanas. En la zona del entorno se encuentran abundantes testimonios romanos (LosTAL, J., Arqueologia del Aragon romano, Zaragoza, 1980, págs. 18-26). La "civitas" de los "llumberritani" se identifica con Lumbier (Navarra). Se conoce un mosaico que se sitúa en el siglo ॥ (Mezouiriz, M. A., "Prospecciones arqueológicas en Navarra II", P.V.. 118-119, 1970, 
identificación altamente probable o segura, no ofrecen datos para el siglo III d.C., o bien los que hay son tan exiguos e irrelevantes que no permiten hacer un balance cierto sobre el problema. Debemos limitarnos,

pág. 66). En sus proximidades se encuentra la villa romana de Liédena. "lturissa" (muy probablemente Espinal, Navarra. PEREX, M. ${ }^{a}$ J., y UNZU, M., "Notas sobre la posible localización de Iturissa (Espinal-Navarra)", Primer Congreso General..., obra citada, págs. 553562) con restos de edificación, necrópolis, monedas y fragmentos de cerámica común y de T.S.H. por estudiar y definir. Merced a los testimonios arqueológicos la ciudad de "Oeasso" se identifica con la actual Irun. Se dispone en la zona de abundantes testimonios, algunos de (los cuales se sitúan en el siglo II. MiTXELENA, L." "Guipúzcoa en época romana", B.R.S.V., XII, 1, 1956, pág. 75-94; BARANDIARAN, I., "Irún romano", Munibe, XXV, 1, 1973; Ídem, Guipúzcoa en la Edad Antigua, 2." ed., San Sebastián, 1976, págs. 76-106). "Segia" (Ejea de los Caballeros, Zaragoza) se encuentra en una zona con abundantes testimonios de época romana. Se supone que en dicha zona hubo algunas destrucciones que se atribuyen de forma hipotética a las invasiones de francos y alamanes (PEREX, M. ${ }^{a} \mathrm{~J}$., LOS Vascones...", obra citada, pags. 215-228. especialmente pag. 226). "Tarraga" con identificación probable en Los Bañales, Uncastillo (Zaragoza), con abundantes restos urbanísticos y edificios públicos situados cronologicamente de manera general en el Alto Imperio y varias "villae" en el entorno con materiales que llegan al Bajo Imperio (GaLlay, $J$, "Las excavaciones del plan nacional en Los Bañales de Sadaba". Inf. y Mem. de la Comis. General de Excav., núms. 4 y 6. Madrid, 1944 y 1948; BELTRAN, A., "Las obras hidráulicas de Los Bañales (Uncastillo, Zaragoza)", en Segovia y la Arqueologia romana, Barcelona, 1977. págs. 92-129; BELTRAN, F., "El planteamiento urbano de Los Bañales", Symposium de ciudades augústeas, Zaragoza, 1976, vol. II, págs. 153-164; AGUAROD, C., "Avance al estudio de la ceramica de Los Bañales". XIV CAN. Zaragoza, 1977; LostaL, J., Arqueologia del Aragón...", obra citada, págs. 60-90). "Graccurris" se identifica con Eras de San Martin. Alfaro (La Rioja). El lugar ha proporcionado restos arquitectónicos y materiales arqueologicos, que van desde la Edad del Hierro hasta el Bajo Imperio, y monedas (HERNANDEZ VERA, J. A., Y CASADO, P., "Graccuris: La primera fundación romana del Valle del Ebro", Symposium de ciudades augústeas... obra citada, págs. 23-29; Gomez PANtoja, J., "Sobre un posible catastro romano en el límite navarro-riojano", $P . V ., 148-149,1977$, págs. 423-433: HeRnANDEz VERA, J. A., "Alfaro. Campaña, 1982". Mem. de las actuac. program. en el año 1982, Madrid, 1983; PASCuAL M. P., Y MORENo, F. J., "Prensas de aceite romanas en La Rioja», A.E.A., 53, 1980, pág. 202.) "Cascantum" (Cascante, Navarra) era una ciudad importante de epoca republicana y con una comunidad significada en el siglo $\mathrm{V}$, pues sus honorati et possessores se encuentran entre los firmantes de los escritores remitidos al papa Hilario en favor del obispo Silvano de Calahorra. Desconocemos la estructura urbana de "Cascantum". En el 1970 se puso al descubierto un edificio con pavimento de opus signinum. Los materiales, bastante revueltos, acumulados sobre el pavimiento y una capa de tierra quemada parecen indicar que la casa fue ocupada desde mediados del siglo I hasta el siglo $॥$, pues faltan materiales de finales de este último siglo (MEZOuiriz, M. ${ }^{.} A$., "Descubrimiento de pavimientos de opus signinum en Cascante (Navarra)". Homenaje a $D$. J. Esteban Uranga, Pamplona, 1971, págs. 277-307; Idem, "Recientes hallazgos de Arqueologia romana en Navarra", en La romanización del Pais Vasco..., obra citada, págs. 265-271). No se conoce realmente si este edificio pertenecia a una "villa", o se trataba de una casa integrada en el complejo urbanístico. El ánfora vinaria encontrada en la parte baja del pueblo actual corresponde al siglo I (MEZQuiriz, M. ${ }^{a}$ A., "Hallazgo de un áfora vinaria en Cascante", P.V., 88-89, 1962, págs. 417-418).

La ciudad de "Andelos" (Andión. Navarra), que abarcaba unas 18 has., ha sido objeto de varias excavaciones que han aportado abundantes restos arquitectónicos y materiales arqueológicos que permiten seguir la evolución cronológica de la ciudad desde un asentamiento prerromano, pasando por un desarrollo urbanístico de finales de la República y comienzos del Imperio hasta un mayor auge y prosperidad en el siglo II. El decaimiento de la ciudad ha podido producirse quizá a partir de la segunda mitad del siglo II con el posible y progresivo desplazamiento de las gentes acomodadas de la ciudad a las villae rusticae próximas (MezouíRIz, M. ${ }^{a}$ A., "Materiales procedentes del yacimiento romano de Andión", P.V., 78, 1960, págs 57-67; Idem, "Pavimentos decorados hallados en Andelos", TAN, 5 , Pamplona, 1986, págs. 237-249; Idem, «Excavaciones arqueológicas en Andelos (Mendigorria-Navarra)", en El solar vascón en la Antigüedad. Cuestiones de lengua, Arqueologia, Epigrafia e Historia, VI Cursos de Verano de San Sebastian, 1989, págs. 63-71. 
por tanto, a aquellas ciudades vasconas y cercanas al territorio vascón que ofrezcan los datos más significativos al respecto. Pero incluso en estos casos aparece enseguida una primera dificultad: un problema de sincronización que resta fuerza o incluso invalida las conclusiones que de los testimonios arqueológicos pudieran deducirse sobre la presencia de los invasores como causantes de los efectos apreciados. El registro de los incendios y destrucciones, asi como de las subsiguientes reconstrucciones, se localiza arqueológicamente "en el siglo II!", "en la segunda mitad del siglo III" y "a finales del siglo III», de modo que su relación con las fechas propuestas para las invasiones - hacia el 260, la primera, y hacia el 275 , la segunda- es demasiado imprecisa para establecer relaciones de causa a efecto. Además se trata, por lo general, de excavaciones pequeñas y parciales, donde cualquier incendio o destrucción cobra un mayor realce, sin que pueda deducirse, sin embargo, que tales hechos hayan alcanzado una gran magnitud y sean generalizables al resto de la ciudad.

Consideremos en primer lugar el caso de Pamplona. En la excavación en 1956 de un pequeño solar situado en la parte antigua de la ciudad se detectó una capa de incendio, cuya coincidencia cronológica, en términos generales, con la destrucción parcial de "villa" de Liédena, que se habia atribuido a la supuesta segunda invasión, propició la aplicación a Pamplona del mismo argumento. El incendio en cuestión, que afectaba a una casa, correspondía al estrato IV, nivel A, y los elementos cerámicos exhumados, en especial los fragmentos de lucernas del tipo Dressel 17, permiten situarlo, sin más precisiones, en el siglo III d.C. ${ }^{15}$. Sin embargo, la calle romana ("cardo") descubierta durante esa excavación, construida durante el siglo \| y que porporcionó una estratigrafía completa, ofece materiales arqueológicos desde el siglo I hasta el siglo IV sin solución de continuidad ${ }^{16}$.

La excavación del año $1965^{17}$, realizada en un lugar próximo a la de 1956, ofrece en el estrato más profundo unas probables cloacas, entre cuyos muros se acumularon materiales arqueológicos - monedas, lucernas y otros restos cerámicos-correspondientes al siglo I d.C.; los ma-

${ }^{15}$ Ver al respecto Mezouiriz, M. ${ }^{a}$ A.. "Excavación estratigráfica en el área urbana de Pompaelo", P.V., 65, 1956, págs. 467-471.

${ }^{16}$ Mezouiriz, M. ${ }^{2}$ A., Pompaelo II, Pamplona, 1978, págs. 13-14.

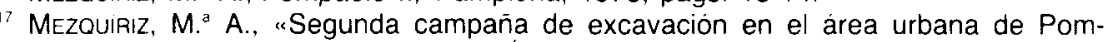
pelo", P.V., 100-101, 1965, págs. 379-384; Ídem, "Excavación estratigráfica de Pamplona (campaña 1965)", en IV Simp. de Prehist. Penins.. Pamplona, 1966, págs. 165-168, Idem. "Excavación estratigráfica de Pompaelo (campaña de 1965)", N.A.H., X-XII. 1969. 
teriales hallados en ese estrato - vidrios, lucernas de disco, cerámicas de los siglos I y II, monedas de Nerva, Faustina, Cómodo y Alejandro Severo como más reciente - llevan a datarlo en el siglo ॥ o comienzos del III. Por encima hay un estrato con monedas bajoimperiales y cerámica de los siglos IV y $v$. No se han apreciado huellas de incendio. Tampoco se encontraron en la pequeña excavación realizada en 1972 en la plaza de San José, donde, sobre restos arqueológicos pertenecientes a los siglos I-II, se superpusieron muros de época bajoimperial (siglos IV-V). Hay que tener en cuenta, no obstante, que, al tratarse de un lugar muy cercano a la catedral, el terreno pudo haber sido removido varias veces.

Es precisamente en esa excavación de 1972, pero en terrenos del antiguo arcedianato, que ofrecen una estratigrafía clara, donde se aprecia en el estrato III, perteneciente al siglo III d.C., una capa de tierra con restos de carbón y abundantes cenizas indicativas de un incendio, que ya se habia registrado en excavaciones anteriores en un lugar muy próximo. Este hallazgo puso de manifiesto que el incendio habia sido más amplio de lo que inicialmente se apreció, pero, no habiéndose detectado en otros lugares excavados, parece impropio generalizarlo a toda la ciudad. $Y$, en cualquier caso, insistimos en que no es posible sincronizar ese incendio con las invasiones de un modo fehaciente ${ }^{18}$.

Por lo demás, junto a los cimientos del lienzo de muralla exhumado en 1980 en el claustro de la catedral aparecen abundantes materiales del siglo I d.C., pero también algunos fragmentos cerámicos bajoimperiales, lo que ha hecho pensar que su construcción corresponde a finales del siglo III o comienzos del IV; no puede considerarse, por tanto, como una consecuencia directa de las invasiones ${ }^{19}$.

Tampoco está claro que la ciudad de "Calagurris" haya sufrido los efectos de las invasiones. La consideración del amurallamiento de esa ciudad en época bajoimperial como una consecuencia del temor inspirado

18 En las excavaciones del año 1972, realizadas en terrenos próximos a aquellos en los que se excavó anteriormente, se apreció también la capa de incendio detectada en campañas anteriores (MezouiRiz, M." A., "Segunda campaña...", obra citada, pág. 379). Esto indicaba que el incendio puesto ya de manifiesto en una campaña anterior era más amplio de lo que inicialmente se suponia, lo que reforzaba la consideración de que se debia a las invasiones barbaras (MEZQUIRIz, M. ${ }^{a}$ A., "Algunas aportaciones al urbanismo de Pompaelo". Symposium de ciudades auguisteas .... obra citada, pag. 192). Posteriormente a esa propuesta hipotética, BLAZQuEZ, J. M. (La crisis del siglo II..., obra citada, pág. 465), y PEREX. M. A. (Los Vascones... obra citada, pag. 202), hacen a los invasores francos y alamanes los probables causantes del incendio de Pamplona.

19 Mezouiriz, M. ${ }^{a}$ A., "Localización de un lienzo de la muralla romana de Pompaelo", Homenaje al Prof. Martin Almagro Basch. Madrid, 1983, vol. III, págs. 275-277. 
por los bárbaros se hace de una manera altamente hipotética, en razón a los datos imprecisos y poco significativos obtenidos en unas prospecciones arqueológicas limitadas. El espacio entre los parámetros de la muralla se rellenó con abundantes materiales cerámicos del siglo I d.C., lo que ciertamente aclara poco la cuestión relativa al momento en que pudieron construirse las murallas ${ }^{20}$. La probable reducción del perimetro urbano y el progresivo abandono de la periferia de la ciudad - que parece atestiguar el abandono de la casa exhumada en el solar de La Clínica- podrian abedecer a un languidecimiento de ese centro urbano como tal más que a la acción destructora de los bárbaros ${ }^{21}$.

La ciudad de los "Carenses", identificada con la actual Santacara, fue objeto de excavaciones arqueológicas limitadas. Los materiales encontrados situan el apogeo de la ciudad en el siglo II, de modo que, si consideramos, como parece razonable, que la capa de incendio detectada en la zona excavada es cronológicamente inmediata a dicho apogeo, sugerido por diversos testimonios, no podriamos datarla en la segunda mitad del siglo III. Lo que si es probable es que la ciudad haya entrado tras el incendio en una fase decadente, lo que podría explicar el hecho de que Ptolomeo no la mencione entre las ciudades atribuidas a los vascones; pero tal decadencia parece ser anterior a las convulsiones del siglo $\mathrm{III}^{22}$.

Por lo que respecta a las ciudades próximas al territorio vascón, el incendio que experimentó el poblado de Inestrillas no puede generalizarse a todo el lugar. Tampoco la construcción de las murallas, que se

${ }^{20}$ Para los pocos datos que se dispone de la muralla ver Gomez Pantoja, J., “La ciudad romana de Calahorra", Symposium de ciudades augústeas..., obra citada. pág. 85; Martin Bueno, M., y Cancela, M. ${ }^{a}$ L., "Arqueología Clásica de Calahorra y su entorno", en Calahorra. Bimilenario de su fundación, Madrid, 1984, pág. 85.

${ }^{21}$ Para la reducción del perimetro de la ciudad y el progresivo abandono de la periferia ver Gutierrez, P., "Calagurris lulia Nassica”, Berceo, 7, 1948, págs. 201-202; Ídem, "Historia de la muy noble, antigua y leal ciudad de Calahorra", Berceo, 38, 1956, págs. 72-74. Con relación a la casa exhumada en el sitio de La Clínica y que fue abandonada, se supone, por esas fechas, ver ESPINOSA, U., "Excavación en el municipio Calagurris lulia (campaña del 1980)", Expos. de Arqueol. Calagurritana, Calahorra, 1982, pág. 33.

${ }^{22}$ Sobre todos estos aspectos ver MEzQuiniz, M. ${ }^{a}$ A., "Cerámica prerromana hallada en las excavaciones de Santacara (Navarra)", XIV C.A.N., 1977, págs. 599-608; Ídem, "Primera campaña de excavaciones en Satancara (Navarra)", P.V., 138-139, 1975, págs. 83109; Ídem, "Cerámica de importación hallada en la excavación de la antigua Cara", Con. greso Rei Cretariae Romanae Fautores. August (Suiza), 1975; Idem, "Retrato masculino aparecido en las excavaciones de Santacara (Navarra)", P.V., 136-137, 1974, págs. 403404. 
datan a finales del siglo III, puede considerarse en rigor como una consecuencia directa de la presencia de esos bárbaros en la zona ${ }^{23}$.

La capa de incendio del nivel 3a de Varea no corresponde tampoco a todo el asentamiento. Sobre ella se constata una fase que da paso a una "modificación y reconstrucción del espacio constructivo, fechada hacia mediados del siglo III d.C." por los materiales cerámicos encontrados ${ }^{24}$. Los hallazgos monetales tampoco evidencian interrupción. Difícilmente podria deducirse de todo ello que el incendio haya sido debido a la acción de los invasores, de modo que los investigadores hablan tan sólo de una hipotética repercusión indirecta, que no se puede establecer de forma precisa.

En "Lybia», finalmente ${ }^{25}$, se aprecian las huellas de un edificio incendidado, luego reconstruido y destruido de nuevo quizá por un incendio, que se sitúa a finales del siglo in y se considera motivado por las invasiones ${ }^{26}$. Pero se trata de un único edificio, y no se nos informa sobre si el incendio alcanzó a otras construcciones y zonas de la ciudad, como sería de esperar si una ciudad abierta como lo era Lybia hubiera sido atacada por los bárbaros.

También se supone que la hipotética segunda invasión afectó a diversas villae del territorio vascón y zonas adyacentes. En la excavación de la "villa" de Liédena ${ }^{27} \mathrm{~B}$. Taracena constató incendios y destrucciones en la "villa» construida en el siglo $\|$ d.C.; el mosaico de la habitación 27 se encontraba roto en su sector sudoriental, y bajo el nivel del pavimento de los dos sectores descritos por Taracena «había una capa poco gruesa de incendio» ${ }^{28}$. Pero el incendio, que generaliza a toda la "villa»

${ }^{23}$ Hernandez Vera, J. A., Las ruinas de Inestrillas. Estudio arqueológico, Logroño, 1982, pág. 135.

${ }^{24}$ Galvez, P., y ANDRES, S., "Excavaciones arqueológicas en Varea. Tercera campaña", en / Coloquio sobre Historia de La Rioja, Logroño, 1983, pág. 108; GALVEZ, P.. Y ANDRES, S., "Hallazgos numismáticos en el yacimiento romano de Varea", Calahorra. Bimilenario de su fundación..., obra citada, págs. 69-76.

${ }_{25}$ Marcos Pous, A., y Castiella. A., "Estratigrafía en la zanja A-M-1", Berceo, 81, 1971, págs. 111-126; Marcos Pous, A., Trabajos arqueológicos en la Libia de los Berones, Logroño, 1979, págs. 82-83, pág. 121.

${ }^{26}$ Ver al respecto VILLACAMPA, M. A., Los Berones según las fuentes escritas, Logroño, 1980 , págs. 88-89.

${ }_{27}$ TaRacena, B., "La villa romana de Liédena. Capitulo I", P.V., 1949, págs. 353-382; Idem, "La villa romana de Liédena. Capitulo II», P.V., 1950, págs. 9-50; İdem, Excavaciones en Navarra II (1947-1951). Pamplona, 1956, págs. 45-106.

28 TARACENA, B., "La villa romana de Liedena...". Excavaciones $11 . .$. obra citada, pág. 88; Mezouiriz, M. ${ }^{a}$ A., Los mosaicos de la villa romana de Liédena, XVII, 1956, págs. 9-35; Ídem, Excavaciones 1/..., obra citada, págs. 189-212, aqui pág. 209: “el mosaico está per- 
al considerar que fue destruida, no se detecta en todas las habitaciones próximas que rodean el peristilo. Éste, que se encontraba en buen estado, fue reutilizado en el momento de la reconstrucción y ampliación de la "villa", siendo los muros que la rodean los que, debido a la superposición de fases que presentan, han llevado a la confusión, en un sector concreto, entre la "villa" antigua y la reciente. Pero, en cualquier caso, se trata de un incendio localizado.

La "villa" de Liédena no sólo aporta materiales que se sitúan cronológicamente desde el siglo $\|$ al $\mathrm{IV}^{29}$, sino que la "villa" antigua sufrió arreglos que, en función del mosaico, pueden fecharse en el siglo $\mathrm{II}^{30}$. Por supuesto que tales reformas no se pueden datar con mayor precisión, pero lo mismo ocurre con esa "capa poco gruesa de incendio" que Taracena atribuyera a los invasores. Es, en definitiva, el tesorillo encontrado en este "villa" con la moneda más reciente acuñada en tiempos de Quintilio (año 270 d.C.), lo que se utilizará como argumento de más fuste para postular la incidencia de la invasión. El tesorillo de Liédena ha de ponerse en relación tanto con los tesorillos galos más próximos a tierras hispanas como con los de la Meseta Norte de la Península, por donde se supone que discurrieron los supuestos invasores. Ahora bien, en ese sentido conviene significar que los tesorillos galos no sólo disminuyen sustancialmente, como era de esperar en razón al progresivo alejamiento de los focos invasores, conforme nos acercamos a los Pirineos, sino que, además, en términos generales, los galos ofrecen una cronología entre los años 274-275 ligeramente posterior a los hispanos, situables cronológicamente entre los años $268-270^{31}$. Y esto último sí encaja mal, en principio, con la progresión geográfica que debería haber seguido la supuesta invasión. Las monedas del tesorillo de Liédena pertenecen a emperadores con gobiernos situados entre el 244 y el 270 , lo que da

fectamente acabado por tres de sus lados, en tanto que por uno... se encuentra roto, al parecer desde antiguo, y posiblemente esta parte de la casa se hallaba en reparaciones en el momento que fue destruida o saqueada, pues al lado de la rotura del mosaico se han encontrado montones de mortero".

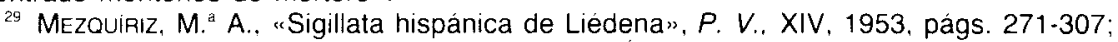
Ídem, Excavaciones II... obra citada, págs. 109-143; Idem, "Estudio de los materiales de la villa romana de Liédena". P.V., XV, 1954, págs. 30-54; Idem, Excavaciones II..., obra citada, págs. 145-170.

${ }^{30}$ Mezouiriz, M. ${ }^{a}$ A., "Los mosaicos...", en Excavaciones 1/..., obra citada, pág. 212.

${ }^{31}$ Para la distribución y cronologia progresiva de la ocultación de los tesorillos galos conforme nos acercamos a las tierras hispanas, ver BLANCHET, A., Les Tresors de monnaies romaines et les invasions germaniques en Gaule, París, 1900; KOETHE, H., "Zur Geschichte Galliens im dritten Viertel des 3. Jahrhunderts", Ber. Röm. Germ. Komm., 32, 1950, págs. 199-224. 
para su ocuitamiento teórico una fecha ligeramente anterior a la de los tesorillos galos más próximos; y lo mismo ocurre con el tesorillo de Sangüesa, cuya moneda más reciente corresponde a Póstumo.

No muy distante de la "villa" de Liédena, en el límite entre Navarra y Zaragoza, se encuentra la "villa» de Rienda (en Artieda, Zaragoza). Las prospecciones y sondeos arqueológicos efectuados pusieron al descubierto una "villa" ${ }^{32}$ en la que se detectó el incendio y desalojo de una casa. El mosaico encontrado parece corresponder a finales del siglo $1{ }^{33}{ }^{33}$. Resulta, en verdad, una coincidencia atractiva, pero, ciertamente, como señala E. Osset ${ }^{34}$, el momento y el motivo del abandono del edificio no están determinados.

La factoria vinicola de Funes ${ }^{35}$ se mantiene en pie hasta mediados del siglo III, pero sin que su abandono, del que por otra parte no hay datación precisa, esté motivado por los invasores. La "villa» descubierta en Villafranca de Navarra ${ }^{36}$, cuyo arranque parece corresponder al siglo II, se reforma, de acuerdo con los materiales encontrados, a finales del siglo III o comienzos del IV, pero la reforma no se hace aprovechando un posible deterioro causado por los invasores.

El resto de las villae del territorio vascón, como las de Falces, Soto de Ramalete, Arróniz, Corella y Mues ${ }^{37}$, tampoco ofrecen síntomas de la

${ }^{32}$ Beltran, A., y OsSet, E., "Nota sobre hallazgos romanos en Artieda de Aragón (Zaragoza)", VIII C.N.A.. 1963, págs. 448-450; OSSET, E., "Hallazgos arqueológicos en Artieda de Aragon". A.E.A., 38. 1965, pags. 8-99.

33 OSSET, E.. "La villa romana de Rieda, en Artieda de Aragón (Zaragoza)", A.E.A., 40, 1967, págs. 120-128.

${ }_{34}$ OSSET, E., "La villa romana de Rieda...", obra citada, págs. 120 ss.

${ }^{35}$ DE Navascues Y DE PALAcio, J., “Descubrimiento de una bodega romana en término de Funes (Navarra)", P.V., LXXVII, 1959, págs. 227-229.

${ }^{36}$ Mezoviriz, M. ${ }^{a}$ A., "Hallazgo de mosaicos romanos en Villafranca (Navarra)", P.V., 124-125, 1971, págs. 177-188; Idem, "Recientes hallazgos de arqueologia romana en $\mathrm{Na}$ varra", en La Romanización del Pais Vasco. Estudios de Deusto, vol. XX, 1972, págs. 276280 .

${ }^{37}$ En el pueblo de Falces (Navarra), en cuyo termino municipal se han detectado varias villae rusticae. se excavó una villa (MEzouiriz, M. ${ }^{a}$ A., "La excavación de la "villa" romana de Falces (Navarra)". P.V.. XXXII, 1971, pags. 49-75; idem, "Recientes hallazgos...", en La Romanización del Pais Vasco.... obra citada, págs. 273-276) que ofrece dos edificaciones superpuestas. De la más antigua, sólo se dispone de restos arquitectónicos. La otra edificación. por los materiales en ella encontrados, corresponde al siglo iv. No hay indicios de que el paso de una a otra edificación esté marcado por destrucciones o perturbaciones. Por lo tanto, no se puede considerar como consecuencia de las invasiones. De manera semejante, la villa de Soto de Ramalete (TARACEnA, B., y Vazduez de PARGa, L., "La villa romana del Ramalete (término de Tudela)", en Excavaciones en Navarra II.., obra citada, págs. 4-42; GARCIA y BELLIDO, A., "Dos villae rusticae recientemente encontradas", A.E.A., 26, 1953, págs. 214-217) alcanza su desarrollo constructivo a mediados del siglo IV a partir 
presencia y de las destrucciones de esos supuestos invasores. Tampoco las villae cercanas a tierras vasconas acusan destrucciones o que éstas puedan atribuirse con seguridad a los invasores. La "villa" de Cabriana (Álava), con una ocupación desde el siglo I al IV, padeció un incendio hacia los últimos años del siglo $\|$ y comienzos del $11{ }^{38}$. Nada tienen que ver, por tanto, con los acontecimientos de la segunda mitad del siglo III.

Si los territorios vascónicos hubieran soportado una invasión que afectara a ciudades y villae, con un rosario de saqueos y destrucciones, dicha invasión deberia haber afectado también a las comunicaciones, sembrando la intranquilidad en los caminos y aumentando los riesgos del tránsito por ellos de hombres y de mercancias. En definitiva habría contribuido con su molesta presencia, moviéndose de un lugar a otro, al deterioro de las vias y al abandono de las reparaciones que dichas vías exigian con relativa asiduidad. Pero no parece que tal cosa haya ocurrido en los caminos del territorio vascón. Las dos vías más importantes que discurren por tierras vasconas lo hacen por su parte meridional y noroccidental. De estos dos sectores viarios no se dispone por ahora de miliarios. Sin embargo había dos caminos, no recogidos en el Itinerario Antoniniano, que eran esenciales en las comunicaciones internas de Vasconia. Una es la denominada convencionalmente Vía de Las Cinco Villas, y la otra la que desde Jaca llegaba a Varea. Son éstas las que han proporcionado varios miliarios del siglo III que testimonian la actividad no interrumpida de las comunicaciones a lo largo de este siglo de crisis y de dificultades. De Caracalla se dispone de un miliario del año 216 pro-

\footnotetext{
de una ocupación anterior que no puede precisarse. En Arróniz (Navarra) hay indicios de una villa que se embellece, a juzgar por los testimonios obtenidos a finales del siglo 11 o comienzos del IV (DE AnSOlEAGA, F., "Monumentos romanos de Arróniz", B.R.A.H.. 62, 1913, pág. 385; B.R.A.H., 64, 1914, págs. 83-92; FernANDEZ DE Aviles, A., "El mosaico de las Musas de Arróniz y su restauración en el Museo Arqueológico Nacional", A.E.A., XVIII, 1945, págs. 342-3507). En Árbol Blanco, en Corella (Navarra), se han encontrado indicios de una "villa" que ha proporcionado abundantes materiales cerámicos de finales del siglo III y comienzos del iv (Mezquiriz, M. ${ }^{\text {a }}$ A., "Prospecciones arqueológicas en Navarra", P.V.. 108-9, 1967, págs. 243-244). Tampoco en la "villa" de Mues, objeto de pequeñas prospecciones. y que por los materiales obtenidos parece que se ocupa a finales del siglo III o comienzos del iv, ofrece datos que hagan pensar que dicha "villa", lo mismo que las otras señaladas, guarden relación con los invasores o sean una consecuencia de la presencia de los mismos en esa zona.

${ }^{38}$ En tierras alavesas, en el limite entre las provincias de Burgos y Álava, existe una rica "villa", la de Comunión, Cabriana (Álava), que ha proporcionado abundantes materiales. Estos indican que el lugar está ocupado desde el siglo । hasta el IV. La "villa" sufrió un incendio hacia los últimos años del siglo " y comienzos del III. (TORRES, M., "Los mosaicos descubiertos en el sigio xvill en la villa de Cabriana (Álava)", E.A.A., 10, 1981, págs. 311 y 336).
} 
cedente de Castiliscar. De Maximino y Máximo, tres miliarios del año 238 procedentes de Eslava, Santacara y, el tercero, de procedencia desconocida. De Carcastillo, un miliario del año 252-253, de Treboniano y Volusiano. De Valeriano y Galieno, sin poder concretar fecha por el mal estado de conservación, un miliario procedente de Castiliscar. De M. Aurelio Probo, el emperador que en las Galias combatió a aquellos invasores que supuestamente penetran en Hispania, se dispone de un miliario -entre los años 276-278- aparecido en Eslava. De Aurelio Caro (282283), uno aparecido en Santacara; de Aureliano Numeriano (283-284), uno procedente de Santacara y otro de Castiliscar, y de M. Aurelio Carino (283-285), uno aparecido en Castiliscar. 